\title{
Improving the Science-Policy Interface of Biodiversity Research Projects
}

\begin{abstract}
Against the background of a continuing biodiversity loss there is a strong need to improve the interfaces between science and policy. Many approaches for such interfaces exist, the most recent being the Intergovernmental Platform on Biodiversity and Ecosystem Services (IPBES).
\end{abstract}

A less prominent approach to interface science with policy consists of research projects directly linking with decision makers. Here we present insights and recommendations on how to do this successfully, highlighting among others the role offacilitating mutual learning and enhancing interface expertise in institutions.

Carsten Neßhöver, Johannes Timaeus, Heidi Wittmer, Annamaria Krieg, Nicoleta Geamana, Sybille van den Hove, Juliette Young, Allan Watt

Improving the Science-Policy Interface of Biodiversity Research Projects | GAIA 22/2 (2013): 99-103 | Keywords: European biodiversity research, Horizon 2020, IPBES, Science-Policy Interfaces for Biodiversity: Research, Action, and Learning (SPIRAL), transdisciplinary approaches

\section{A Focus on Science-Policy Interfaces of Research Projects}

The loss of biodiversity continues unabated due to anthropogenic pressures linked notably to economic and population growth, land- and sea-use changes, invasive species, climate change and the lack of adequate policies addressing them (GBO3 2010). Indeed, some authors have attributed the continued loss of biodiversity to "a collective failure of the science-policy process" (Larigauderie and Mooney 2010 b, p. 1), or the "knowing-doing gap", or the divide between science and policy in the context of conservation biology (Knight et al. 2008). The shortcomings of sciencepolicy interactions were further emphasised in a United Nations Environment Programme (UNEP) gap analysis. It identified a need to strengthen the biodiversity science-policy interface (SPI) to address environmental problems at the global scale (UNEP 2009) and supported the decision of many UN member countries to set up the Intergovernmental Science-Policy Platform on Biodiversi- ty and Ecosystem Services (IPBES) to fill this gap (Van den Hove and Chabason 2009, Görg et al. 2010, Larigauderie and Mooney 2010 a). Although the weakness of the SPI on biodiversity is surely not the only reason for the persistence of biodiversity loss, it has become one key concern over recent years.

Efforts to improve the SPI often focus on large-scale, top-down approaches such as scientific assessments like the Millennium Ecosystem Assessment (MA) (2005) and The Economics of Ecosystems and Biodiversity (TEEB) (2009). They may also concentrate on setting up permant institutions such as IPBES to provide further assessments and other policy support activities, to establish continuous exchange platforms. Similar approaches exist at the regional and national scale, for example, in the work of national advisory bodies. Yet an important level at which science and policy interact is in small- to large-scale research projects. These projects can help align research processes and outcomes to the needs of policy makers, other stakeholders and society in general, enabling a direct exchange of knowledge and perspectives.
Contact: Dr. Carsten Neßhöver | Tel.: +493412351649 | E-Mail: carsten.nesshoever@ufz.de

Johannes Timaeus, M.Sc.|E-Mail: johannes.timaeus@ufz.de both: Helmholtz-Centre for Environmental Research - UFZ | Department of Conservation Biology | Permoserstr. 15 | 04378 Leipzig | Germany

Dr. Heidi Wittmer | Helmholtz-Centre for Environmental Research - UFZ | Department of Environmental Politics | Leipzig | Germany | E-Mail: heidi.wittmer@ufz.de

(C) 2013 C. Neßhiover et al.; licensee oekom verlag. This is an Open Access article distributed under the terms of the Creative Commons Attribution License (http://creativecommons org/licenses/bp/3.0), which permits unrestricted use, distribution, and reproduction in any medium, provided the original work is properly cited.
Annamaria Krieg, M.Sc. I Royal Netherlands Institute for Sea Research (NIOZ) | t Horntje | The Netherlands | E-Mail: annamariekrieg@gmail.com

Dr. Nicoleta Geamana | University of Bucharest | Research Center of Systems Ecology, Eco-diversity and Sustainability | Bucharest | Romania | E-Mail:nicoleta_geamana@yahoo.com

Dr. Sybille van den Hove | Median S.C. P. | Barcelona | Spain |

E-Mail: sybille@median-web.eu

Dr.juliette Young | E-Mail: jyo@ceh.ac.uk

Dr. Allan Watt | E-Mail: adw@ceh.ac.uk

both: NERC Centre for Ecology and Hydrology | Edinburgh | United Kingdom 
Biodiversity loss is a "wicked problem". As with many environmental challenges, it cannot be solved merely by established approaches to policy, science and linking science and policy making (Sharman and Mlambo 2012), but calls for transdisciplinary approaches (Hirsch Hadorn et al. 2008, Jahn et al. 2012) to research. By transdisciplinary approaches we understand work that "moves beyond the domain of disciplinarity, generating new approaches to scientific knowledge production that either transcend the formalism of a discipline altogether and/or operationalize integrative collaborations between academics and non-academics, such as local communities and/or policy-makers, as a core part of the scientific work" (Farrell et al. 2013, p. 36).

In other words, the biodiversity issue calls for direct sciencesociety interaction between researchers and stakeholders such as policy makers as well as those using the benefits of, caring for or being constrained in their activities by biodiversity. Such direct interactions are a key aspect of the overall SPI landscape, including SPI activities of research projects. Even if most projects will not follow a complete transdiciplinary approach and only take up elements from it, they, nonetheless, contribute to mainstreaming the idea of transdisciplinarity.

In this paper, we report and reflect on insights gained from 34 in-depth interviews on five European Union (EU) research projects $^{1}$ to capture all experiences gained in designing and conducting SPI activities at project level and to better understand their challenges and potentials. These insights were complemented by a workshop discussion on lessons learned from the interviews on SPI activities in EU projects. The workshop brought together scientists with experience from over $50 \mathrm{EU}$-funded research projects, experts from the European Environmental Agency and its topic centre on biodiversity, and policy makers from the European Commission.

The detailed results can be found in a report (SPIRAL 2012) and policy briefs specifically addressing the needs and opportunities of research funders, environmental policy makers and researchers ${ }^{2}$. From these results we identify overarching challenges and how they could be tackled. We conclude with suggestions for improving SPI activities at project level aimed at researchers and at policy makers operating at national, European and international levels.

- EU-wide Monitoring Methods and Systems of Surveillance for Species and Habitats of Community interest (EuMon): http://eumon.ckff.si

- Assessing Large-scale Environmental Risks with Tested Methods (ALARM) www. alarmproject. net/alarm

- Hotspot Ecosystem Research on the Margins of European Seas (HERMES): www.eu-hermes.net

- Assessment of Environmental and Resource Costs and Benefits in the European Water Framework Directive (AQUAMONEY). www.ivm.vu.nl/en/projects/Projects/economics/aquamoney

- A Long-Term Biodiversity, Ecosystem and Awareness Research Network (ALTER-Net): http://alter-net.info

2 For report and policy briefs see also the Science-Policy Interfaces for Biodiversity: Research, Action, and Learning (SPIRAL) website www.spiral-project.eu.

\section{Main Challenges and Lessons Learned for Biodiversity Research Projects at the EU Level}

Considerable efforts have been made to strengthen SPIs at project level. Research projects are increasingly required to include SPI activities as mandatory elements in their work plan and to outline the expected impact that the research project may yield with respect to relevant policies. In many projects this has led to the development of a number of approaches to improve their science-policy interfaces, such as creating policy advisory boards or similar bodies where scientists and potential users from policy sectors and the wider society may interact regularly. In addition to advisory bodies, projects are increasingly designing specific products targeted towards policy, such as policy briefs, databases or science-policy workshops. These approaches allow projects to interact directly and informally with selected policy actors and can thus play a role in the overall SPI landscape.

However, although efforts have been made to improve the SPI at the project level, frustrations remain for both science and policy actors. Policy makers interviewed highlighted difficulties in

Snake's head fritillary (Fritillaria meleagris) is just one of many endangered species in Europe. To address the loss of biodiversity, researchers and decision makers need to strengthen their interaction, especially in science policy interfaces on research project level or in Europe-wide networks like ALTER-Net, which promote biodiversity research for policy.

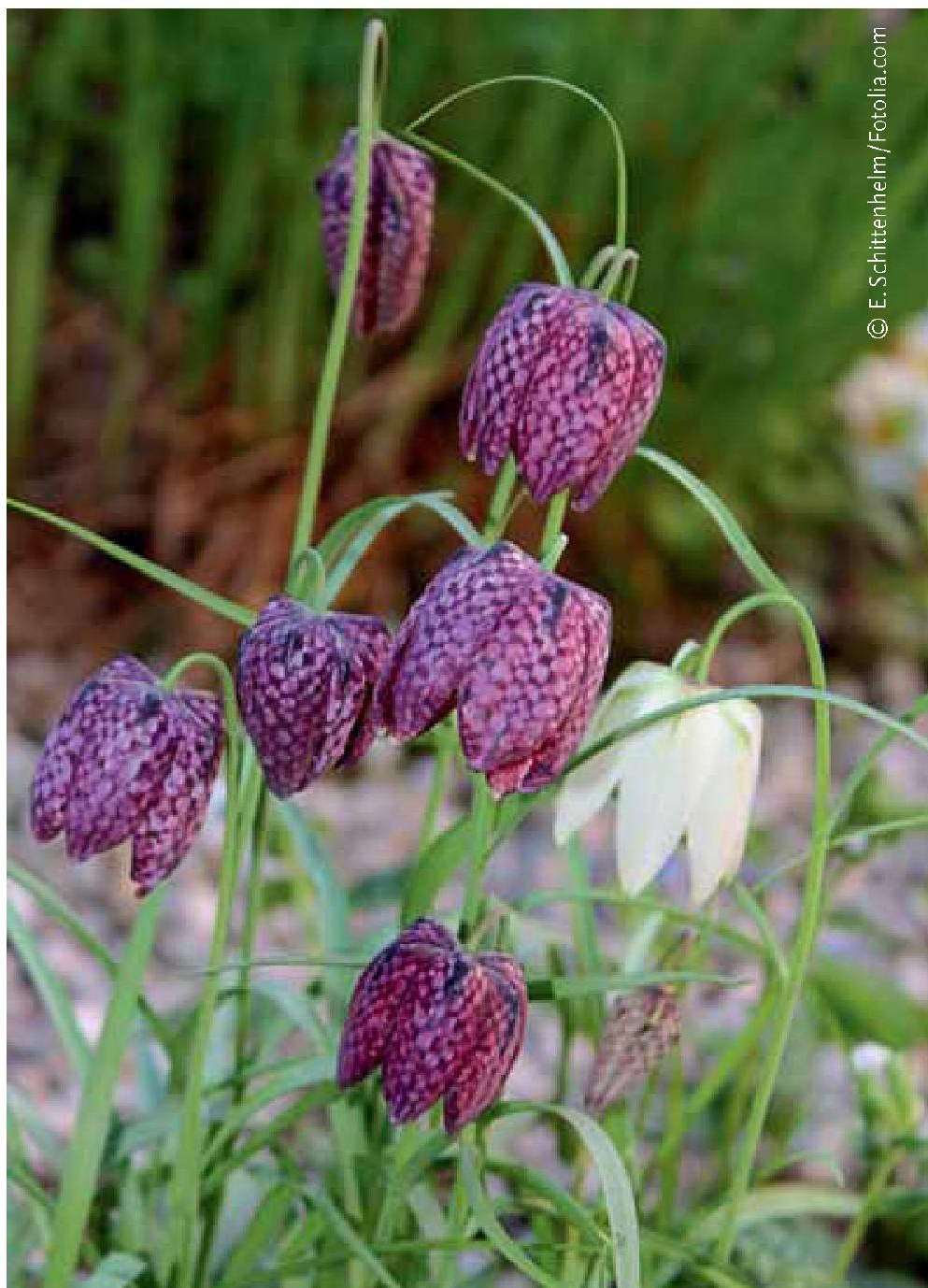


obtaining information from past and ongoing research projects. Indeed, they often found it hard to quickly identify relevant projects, knowledge is often not available in policy-relevant formats, and after a project's end it can be complicated to identify relevant contact persons. The researchers interviewed mentioned the challenges in getting policy actors to take part in their science-policy activities due to time constraints and in getting them interested in their specific topics and findings. Thus, research projects are still facing basic challenges in planning and implementing the interface work, especially in:

- framing and addressing the broader policy context of a project,

- ensuring continuity of interactions between science and policy making to facilitate mutual understanding,

- enhancing and maintaining expertise and quality of SPI practice and products,

- integrating SPI activities between different projects as well as with external partners.

In the following, we describe the main challenges within these four areas in more detail and how they can be addressed. While the focus of our work has been on EU-funded biodiversity projects, most of these findings will also apply to larger national as well as other international projects, and to environmental research beyond biodiversity.

\section{Framing and Addressing the Broader Policy Context}

Research projects in the recent EU Framework Programmes are required to outline their expected impact on policies. Many projects, however, still struggle to take into account the needs, constraints and perspectives of practitioners and policy makers when designing and implementing their work plan. In many respects, the continued institutional separation of research planning, research processes and policy processes makes the identification of appropriate stakeholders and the relevance of their projects challenging. A common example highlighted by interviewees and workshop participants was the incompatibility of often specialised research projects and the broad answers or knowledge overviews or specifically tailored input into policy discussions needed by policy makers. Websites of relevant institutions such as the Directorates General of the European Commission are not designed to help identify the relevance or use of projects. As a result, projects have to rely on the existing expertise of project partners or to start from scratch in identifying policy needs and relevant stakeholders. This leads to situations - described by many project coordinators - where it is only in later stages of a project that the most promising stakeholders, policy opportunities and policy needs are identified - by which time it can be too late.

The alignment of projects and policy relevance requires a broader understanding of the policy context. Interviewees and workshop participants did suggest options to overcome these challenges. Besides applying more thorough transdisciplinary approaches in research funding and design (ESF 2012, Jahn et al. 2012), which would go well beyond the science-policy interfaces applied today, better entry points have to be developed for research projects and policy actors to get an overview of the strategic policy contexts of projects, and identify what projects are the most relevant, and for whom. Interviewees and workshop participants identified a number of concrete measures to facilitate these entry points, including better websites (both project websites and research funders' websites), more explicit formulation of research tenders, events for groups of research projects to inform them about relevant policy contexts, and targeted exchange between researchers and policy makers taking place upstream of the project design process. All the measures proposed were informed by practical experience, which illustrates that some of the lessons from transdisciplinary approaches can be applied even in the more traditional research context and help them address the challenges identified.

\section{Ensuring Continuity of Interactions and Mutual Understanding}

One of the most important lessons learned mentioned by the majority of interviewees and workshop participants was to ensure continuous interaction throughout the lifetime of the project. Once contacts are established and interactions via advisory board meetings and similar processes take place, the challenge is to achieve a mutual understanding of science and policy actors.

Often, the expectations of scientists and stakeholders in advisory bodies diverge significantly at the start due to the different needs and perceptions described - an issue of supply and demand that is a common at the SPI (Sarewitz and Pielke 2007). Such diverging expectations incur the risk of causing misunderstandings between the participants of an SPI. These misunderstandings may then persist throughout the duration of a project. In many cases this can result in project outputs that may have high scientific value but are poorly adapted to policy needs. Accordingly, frustration grows for policy makers, who are not getting the expected outputs, and for scientists whose research is not used.

In order to develop successful SPIs for a project, it is therefore important to remember that a strategic moment lies in the project design and starting phase. At this point, SPI objectives and activities should be discussed openly and clearly and should reflect the needs and expectations of science and policy participants, explicitly trying to develop a common language from the start. These objectives and activities should then be continuously monitored during the research project to ensure that expectations are still aligned. This is an important precondition for the development of a mutual understanding between scientists and policy participants.

While many issues can be avoided through careful planning and explicit exchange of expectations, "wicked problems" such as the loss of biodiversity can trigger conflicts due to different interests or epistemic perspectives, on different sides - researchers, policy makers and/or other stakeholders. The most salient approach is to reflexively handle such problems and avoid strategies that try to "solve" wicked and therefore irresolvable problems by scientific or technical means (Rittel and Webber 1973). 


\section{Enhancing and Maintaining Interfacing Expertise}

Planning SPI processes, contacting and staying in touch with stakeholders, organising the exchange and feeding results back to SPI partners are resource intensive activities. There needs to be an acknowledgement that SPIs cannot be successful if this work is considered as a minor add-on to the project's work and is delegated to participants inexperienced in such work. Indeed, the lack of institutional "memory" in research organisations on how to establish and maintain science-policy interactions is one major obstacle in the SPI activities at project level. In order to make stakeholder interactions an effective and targeted component of a project, such activities must be led or at least supported by partners experienced in science-policy interactions. These can be scientists interested in SPI work, specialised interface and communication experts, or a combination of both. Many research institutions and organisations are gaining experience in interface activities, ensuring that experiences are passed on from one project to the next. However, more needs to be done.

Internal or external SPI experts may help to identify what type of stakeholder interaction or dialogue is a good fit for both project interests and policy needs. This should include dialogue with stakeholders prior to the projects to identify the right level of interactions. In addition, a science-policy interaction strategy should be developed during the early stages of a project as part of the wider communication strategy, which every larger research project is expected to develop.

Although science-policy activities are still undervalued in most research and policy contexts, many involved in projects are interested and willing to participate in science-policy activities. Accordingly, the science-policy strategy especially of larger projects could include science-policy training activities.

\section{Integrating SPI Activities between Different Projects as well as with External Partners}

Another challenge, yet a possible solution to many of the above challenges, is to use cooperative approaches to support the success and endurance of SPI activities across projects and partners.

Interviewees highlighted encouraging experiences of partnerships between projects that helped increase their interaction with policy, especially at the EU level. Projects working in the same thematic area can significantly increase their impact and visibility by joining forces. Such SPI integration among projects also helps policy makers engage, for example, by having to attend fewer meetings. These collaborative efforts can also depict a broader picture and a more refined input to policy than single projects. Such partnerships can be initiated top-down, if supported by funding agencies, or more informally and bottom-up when initiated by projects themselves.

Another option of external cooperation is to link SPI activities to existing institutions (such as environment agencies) and initiatives such as the Biodiversity Information System Europe (BISE) ${ }^{3}$. $B I S E$ is an online platform collecting policy-relevant information on biodiversity developed by the European Environment Agency in partnership with other European institutions. A future com- ponent of BISE could be a database storing project summaries, results and experts for certain topics in a policy relevant manner, for example, by linking them to thematic policy sectors or parts of significant legislation (SPIRAL 2012). Such a platform can serve as a major entry point for projects to promote their work in a policy relevant manner.

\section{Discussion}

Many studies have emphasised the challenges in designing sound and successful science-policy interfaces, especially on complex and value laden issues with high levels of uncertainty and ambiguity (e.g., Cash et al. 2003, Van den Hove 2007, Koetz et al. 2011, Spierenburg 2012). While the focus of science-policy interfaces is often on larger and/or official processes such as policy-led advisory committees or assessments, science-policy activities of research projects are not to be underestimated. They have led to an increased mutual understanding of policy makers and scientists in the field of biodiversity in Europe. They have also facilitated the direct flow from emerging knowledge into policy and practice, and direct inclusion of policy perspectives into research processes. Contacts established through project SPIs often lead to further interaction beyond the project duration. While major challenges in such interactions remain, certain practical approaches can be developed to improve the effectiveness of research projects' science-policy interfaces. For research projects, such approaches include the need to regard SPI activities as a major part of any research plan, including in particular in the communication strategy. SPI activities can be successful tools in achieving recognition for projects beyond their scientific outputs. In order to be successful, they need to be understood as an integral part of the project and should be addressed and developed carefully throughout the lifetime of the project. It is also essential to be clear about SPI objectives by developing them jointly with scientists, policy partners and other stakeholders early in the project. Involving partners experienced in such interactions can improve the effectiveness.

Despite their advantages and importance, project SPIs have limitations in terms of what they can and cannot do. For example, if policy requires a broad foundation and exhaustive interdisciplinary synthesis, this may be beyond the capabilities of a single project or even a group of projects. In such cases other types of interfaces, for example, broad assessments like the MA or TEEB are needed to complement the work of projects. Science-policy interactions should, indeed, be approached in different, complementary ways, through a variety of interfaces.

Dealing with most of the above issues falls within the responsibility of the scientists leading research projects. They have to ensure that the ambition of the SPI activities are properly aligned with the project's needs and opportunities and must be aware of the limitations that they face. However, responsibility also lies

\footnotetext{
3 http://biodiversity.europa.eu
} 
with policy makers and research funders, as they create the enabling environment for researchers to act at the science-policy intersection (SPIRAL 2012). As such, EU research programmes could help improve the way in which projects address SPI activities. Research funders could support new projects, for example, by encouraging projects to collaborate at the science-policy intersection, by establishing links to policy makers, by providing information platforms, or through dedicated processes and structures ensuring a memory on SPI expertise.

In Europe, the new framework programme Horizon 2020 and its implementation may constitute valuable opportunities in this respect. One major cornerstone, not discussed in detail here, is to ensure that SPI activities are properly acknowledged in scientific careers and project evaluations (see, e.g., ESF 2012).

Science-policy interfaces of research projects are a major and often undervalued building block of the SPI landscape. Further developing their approaches and tools, in parallel with SPI activities via boundary organisations and the forthcoming IPBES (Görg et al. 2010, Spierenburg 2012), will be crucial in the future.

We thank the interviewees and the workshop participants. This research was supported by Science-Policy Interfaces for Biodiversity: Research, Action, and Learning (SPIRAL), an interdisciplinary research project funded under the European Community's Seventh Framework Programme, contract number 244035. The views presented in this paper do not reflect the views of the European Com. mission. Any error or inconsistency is the sole responsibility of the authors.

\section{References}

Cash, D.W. et al. 2003. Knowledge systems for sustainable development. Proceedings of the National Academy of Sciences of the United States of America PNAS 100/14:8086.

ESF (European Science Foundation). 2012. Responses to environmental and societal challenges for our unstable earth (RESCUE). ESF Forward Look-ESF-COST "Frontier of Science" joint initiative. Strasbourg: ESF. www.esf.org/fileadmin/ Public_documents/Publications/rescue.pdf (accessed April 22, 2013).

Farrell, K., S. van den Hove, T. Luzzati. 2013. What lies beyond reductionism? Taking stock of interdisciplinary research in ecological economics. In: Beyond reductionism: A passion for interdisciplinarity. Edited by K. Farrell, S. van den Hove, T. Luzzati. Routledge Studies in Ecological Economics. London: Routledge.

GBO3 (Global Biodiversity Outlook 3). 2010. Global biodiversity outlook 3. Nontreal: Secretariat of the Convention on Biological Diversity. www.cbd.int/ doc/publications/gbo/gbo3-final-en.pdf (accessed April 22, 2013).

Görg, C., C. Neßhöver, A. Paulsch. 2010. A new link between biodiversity science and policy. GAIA 19/3:183-186.

Hirsch Hadorn, G., S. Biber-Klemm, W. Grossenbacher-Mansuy. 2008. The emergence of transdisciplinarity as a form of research. In: Handbook of transdisciplinary research. Edited by G. Hirsch Hadorn et al. Dordrecht: Springer. 19-39.

Jahn, T., M. Bergmann, F. Keil. 2012. Transdisciplinarity: Between mainstreaming and marginalization. Ecological Economics 79: 1-10.

Knight, A. T., R. M. Cowling, M. Rouget, A. Balmford, A. T. Lombard, B. M. Campbell. 2008. Knowing but not doing: Selecting priority conservation areas and the research-implementation gap. Conservation Biology 22/3: 610-617.

Koetz, T., K. N. Farrell, P. Bridgewater. 2011. Building better science-policy interfaces for international environmental governance: Assessing potential with in the intergovernmental platform for biodiversity and ecosystem services. International Environmental Agreements: Politics, Law and Economics 12/1:1-21.

Larigauderie, A., H. A. Mooney. 2010a. The intergovernmental science-policy platform on biodiversity and ecosystem services: Moving a step closer to an IPCC-like mechanism for biodiversity. Current Opinion in Environmental Sustainability $2 / 1-2: 9-14$.
Larigauderie, A., H. A. Mooney. 2010 b. The International Year of Biodiversity: An opportunity to strengthen the science-policy interface for biodiversity and ecosystem services. Current Opinion in Environmental Sustainability $2 / 1-2: 1-2$.

MA (Villennium Ecosystem Assessment). 2005. Ecosystems and human well-being: Our human planet - Summary for decision makers. Washington, D. C.: Island.

Rittel, H.W.I., M. M. Webber. 1973. Dilemmas in a general theory of planning. Policy Sciences 4/2: 155-169.

Sarewitz, D., R.A. Pielke. 2007. The neglected heart of science policy: Reconciling supply of and demand for science. Environmental Science and Policy 10/1:5-16.

Sharman, M., M.C. Mlambo. 2012. Wicked: The problem of biodiversity loss. GAIA 21/4: $274-277$.

Spierenburg, M. 2012. Getting the message across: Biodiversity science and policy interfaces - A review. GAIA 21/2: 125-134.

SPIRAL (Science-Policy Interfaces: Research, Action, Learning). 2012. Improving interfaces between $E U$ research projects and policy making: From the recognition of a need, to recommendations for concrete actions. SPIRAL project report. www.spiral-project.eu/sites/default/files/Recommendations_Spiral\%20 workshop_Oct2012_final.pdf (accessed April 22, 2013).

TEEB (The Economics of Ecosystems and Biodiversity). 2009. The economics of ecosystems and biodiversity for national and international policy makers. Geneva: United Nations Environment Programme (UNEP).

UNEP (United Nations Environment Programme). 2009. Gap analysis for the purpose of facilitating the discussions on how to improve and strengthen the science-policy interface on biodiversity and ecosystem services. Second ad hoc intergovernmental and multi-stakeholder meeting on an intergovernmental science-policy platform on biodiversity and ecosystem services, Nairobi, 5-9 October 2009. UNEP//PBES/2/INF/1. www.ipbes.net/meetings/ Documents/IPBES_2_1_INF_1.doc (accessed April 22, 2013).

Van den Hove, S. 2007. A rationale for science-policy interfaces. Futures 39/7: 807-826.

Van den Hove, S., L. Chabason. 2009. The debate on an Intergovernmental Science-Policy Platform on Biodiversity and Ecosystem Services (IPBES): Exploring gaps and needs. IDDRI Working Papers 1. Paris: Institute for Sustainable Development and International Relations (IDDRI). www.iddri.org/Publications/Collections/Idees-pour-le-debat/ Id_090104_gap_analysis-4Feb.pdf (accessed April 22, 2013).

Submitted February 11, 2013; revised version accepted April 8, 2013.

Carsten Neßhö̈ver

Born 1972 in Cologne, Germany. MSc and PhD in geoecology. Since 2003 at Helmholtz-Centre for Environmental Research - UFZ, since 2009 deputy head of the Department of Conservation Biology. Research interests: sciencepolicy interfaces, biodiversity and ecosystem services.

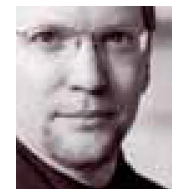

Johannes Timaeus

Born 1981 in Essen, Germany. MSc in Biology. Since 2011 researcher at the Department of Conservation Biology, Helmholtz-Centre for Environmental Research - UFZ. Research interests: science-policy interfaces, participatory approaches in biodiversity policy.

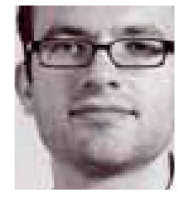

Heidi Wittmer

Born 1964 in Lawrence, Massachusetts. MSc in agricultural sciences, $\mathrm{PhD}$ in socio-economics. Since 2010 deputy head of the Department of Environmental Politics, Helmholtz-Centre for Environmental Research - UFZ.

Research interests: multi-level governance, institutional economics, biodiversity politics. 